DOI https://doi.org/10.36059/978-966-397-226-8-8

\title{
TIME-MANAGEMENT \\ AS BASE COMPONENT IN E-LEARNING
}

\section{Biriukova D. V.}

\section{INTRODUCTION}

Time is the main value of the XXI century. Rationalization of the time spending is an excellent way of self-development and also the release of vital energy for new and interesting things. Time doesn't have an accurate definition, but you notice that the time can't be replaced, stopped, changed or even controlled, the time is available resource when it passes, doesn't return back again any more, it considered just as the valuable element. All this requires some effort, and most importantly, a change in attitudes, some self-discipline. This requires a person to make a decisive reassessment of values and start by mastering new techniques and methods of rational use of the time.

"Time management" does not mean to change, modify or develop the time, but it deals with the question how to invest it in such effective ways, that time spent uselessly or unproductively is reduced to minimum, while attempt to raise productively within the allocated period. This term was borrowed from the economy and in the most general terms means the rational use of the time for additional achievement of maximum labor productivity. This is the "technology of organizing the time and increasing the effectiveness of its use ${ }^{171}$,.

Numerous trainings and master classes, popular science articles, lectures, seminars just prove the relevance of "time management" in all spheres of society, which is overloaded with information and unables to manage time planning. Etzel and Thomas (1996) claim as the 1980s approached, "time management" became a key concept. The point was not just keeping track of details and information any more, it was to

\footnotetext{
${ }^{171}$ Соколов И. М., Железнякова Н. А., Гафанович Е. Я., Коньшина Л. Е., Конобеева Е. В. (2014). Организация занятий в группах студентов 4-го курса медицинского университета с использованием принципов тайм-менеджмента. Альманах современной науки и образования. № 12(90). С. 116-119.
} 
manage time like everyone was increasingly busy, so managing time is essential factor needed to keep success ${ }^{172}$.

Good time management requires an important shift in focus from activities to results: being busy isn't the same as being effective. In today's fast changing life and growing global competitiveness, there is an escalating and ever-growing interest in creativity, novelty and management of the time ${ }^{173}$. The problem of organizing and scheduling class time is far from new. As an independent direction of the organization's management, time management took shape by the end of the 60s of 20-th century. The fundamental studies by D. Allen, B. Tracy, J. Yager, F. Kay and others became essential in the development of time management. The purpose of our research is to reveal the concept of "time management" from the point of view of its applications in the educational process.

Effective time management is the main indicator of organizational capability of an academic staff member of the foreign language because the time is conceptualized as a commodity that requires to be efficiently managed. Time is important for incubation; individuals should be provided with adequate time if they are told to do creative tasks. An academic staff member who follows the time management principles can handle routine functions more effectively and efficiently, leaving more time for important educational concerns. Those academic staff members who manage their time efficiently are ones that are more creative.

\section{Time-management as Pedagogical Technology}

The main development and implementation of pedagogical technologies is associated with the emergence of a technological approach to the construction of education, first in American and then in European researches. Initially, pedagogical technology was understood as an attempt to technize the educational process. Further development of

\footnotetext{
${ }^{172}$ Etzel, Barbara. \& Thomas, Peter (1996). Personal Information Management Tools and Techniques for Achieving Personal Effectiveness. Great Britain : Biddles Ltd Guildford and King's Lynn, London.

${ }^{173}$ Baer, M., \& Oldham, G. R. (2006). The curvilinear relation between experienced creative time pressure and creativity: moderating effects of openness to experience and support for creativity. Journal of Applied Psychology, 91(4), 963.
} 
research in the field of pedagogical technology expanded its understanding, which was reflected in various definitions of this concept by well-known academic staff members and methodologists.

On the one hand, the pedagogical technology "time management" is a process where the interaction between an academic staff member and an undergraduate changes qualitatively and includes all the components of the pedagogical process: purpose, task, contents, principles, methods, forms, tools, results and their evaluation. All these components are determined on the basis of stating the goal and the correlated result. Like any other pedagogical technology "time management" involves the construction of a certain algorithm, the definition of a set of goals, the contents of an undergraduate's individual activity organization in accordance with the requirements of professional competence ensuring the expected outcomes realization. The orientation of undergraduates to the time as the most important value is very important (categories, concepts and patterns of the time management are applied on the basis of an axiological approach: goal-setting according to A. Lakein's method).

On the onter hand, "time management" can be considered as a sequence of special actions based on the use of educational techniques aimed at ensuring effective time use. In practice the "time management" technology is carried out through the technological (pedagogical) process, the functioning of all personal, instrumental and methodological pedagogical means. It is necessary to model the system of personal time management technologies (using a diary, an e-organizer, Internet technologies).

Thus, the pedagogical technology "time management" functions both as methods of activity, offering the most rational ways of teaching, and as principles and regulations used in teaching and as a real learning process.

Time management is a technology that allows the use of irreplaceable life time in accordance with personal and academic goals and values.

Time management as pedagogical technology refers to the technologies of developing education. The undergraduate is assigned the role of an independent subject interacting with the environment. This interaction includes all stages of activity, each of which makes its own specific contribution to personality development. At the same time, the 
important one is the motivational stage, according to the method of organization of which subgroups of developmental education technologies are distinguished, is based on:

1) cognitive interest;

2) individual experience of personality;

3) creative needs;

4) needs for self-improvement.

The main principles of the "time management" technology are: orientation to the time as a value, independent work, individuality of the solution, the need to track one's own effectiveness, thinking aimed at efficiency, attainability and inexhaustibility of efficiency reserves. The pedagogical technology "time management" meets the main methodological requirements - the criteria of manufacturability (conceptuality, consistency, controllability, efficiency, reproducibility) ${ }^{174}$.

"Time management" refers to the way that you organize and plan how long you spend on specific activities. It may seem counter-intuitive to dedicate precious time to learning about time management, instead of using it to get on with your work, but the benefits are enormous. They are:

1) greater productivity and efficiency;

2) better professional reputation;

3) less stress;

4) greater opportunities to achieve important life and career goals.

In return when you manage your time uneffectively some very undesirable consequences can be: missed deadlines; inefficient work flow; poor work quality; poor professional reputation and a stalled career; higher stress level.

How to provide an interesting lesson and implement everything conceived in the plan? One of the main obstacles to a highly effective lesson is a lack of time management skills. In teaching foreign languages the goal of time management is to achieve the highest performance per

\footnotetext{
${ }^{174}$ Реунова M. А. (2013). Тайм-менеджмент как педагогическая технология URL: Письма в Эмиссия. Оффлайн: электронный научный журнал. № 1. URL: http://www.emissia.org/ offline/2013/1947.htm.
} 
unit of time, providing a sufficient level of health saving. The main parts of time management at English lesson are: time tracking, time optimization, task planning and motivation. Espesially, all these points are very important during providing lessons though different on-line conference systems (e.g. Zoom, Meet, etc.)

One of the basic rules of lesson time management is the following:

1. Plan each lesson in writing in detail. It is impossible to conduct highly effective lessons without preparation. Drawing up of a detailed plan will require a certain investment of the time, which will certainly pay off by increasing the effectiveness of the lesson and the level of an academic staff member satisfaction with his / her activity. The detailed plan means that you must define the purpose of the lesson, tasks, ways of their implementation and control forms of results in the algorithm of activities that will be implemented during the lesson.

2. Prioritize and arrange the order of tasks in the descending order of importance:

- after preparation of tasks' algorithm prioritize the tasks and choose those that are the most important to achieve the goals effectively;

- learn how to divide all tasks into four categories: important and urgent; important and non-urgent; unimportant and urgent; unimportant and non-urgent;

- start from the first category of tasks - important and urgent. In this case, if you do not have time to complete some tasks from the last lines of the plan, the main tasks will be completed. With this kind of planning, unimportant and non-urgent tasks have no chance of wasting undergraduates' time. The hardest part is to determine which are the most important and urgent, and not to miss lesson goals.

3. Plan the forms of classroom work at each stage of the lesson:

- form "work blocks" containing tasks of similar nature in accordance with the rules of time management;

- remember that any shift in attention from one type of work to another needs time.

The specific character of teaching activity lies in the fact that it is important to remember about the necessity to change the types of activity during the lesson (as it is said: "change of activity is rest"). 
It is necessary to focus not on "jumping" from one task to another one, but on one of the key principles of organizing highly effective activities, which is often mentioned, but rarely used: "to have a rest before get tired". This is extremely relevant and rather difficult.That means to build the motivation for the activity before it starts. Academic staff members have always had such techniques and methods, and their detailed discussion will allow them to form a basic attitude towards interest in the content. If the undergraduates have developed an inner interest to the topic, if they work enthusiastically, forgetting about everything around, then the change of activities ceases to be a necessity and becomes an obstacle to the deep mastering of the educational material.

Choosing types of educational activities, you need to use the most time-saving ones and at the same time effective in terms of achieving the lesson's goals.

It is important to combine traditional and innovative teaching technologies.

The academic staff member has to master not only new technologies, but - simultaneously with them - new professional roles that complement his / her role as the main mediator of knowledge. The innovative roles will push an academic staff member to expand the "delegation of authority" from the academic staff member to the undergraduates, which will make undergraduates move away from the ineffective passive perception of information to active knowledge acquisition.

4. Establish time limits. The schedule is set for each stage of the lesson and should not be vague, but it should take into account the possibility of a slight decrease or increase (if necessary) in the duration of each stage, when the main objectives of the lesson would be achieved. Furthermore the lesson plan must have some time in reserve in order to deal with unforeseen difficulties that may arise.

Without a clear timing, it is impossible to make a lesson interesting, varied, not tiring and at the same time achieve main educational results.

The regulations should not become a limitation of the cognitive activity of undergraduates. For example, if at a certain stage of work it was possible to organize cognitive activity using gaming technologies, 
and the undergraduates got involved into the game and passionate about the process, then it is difficult to switch them to another type of work. Here, the academic staff member is the only timekeeper, who must think over the forms of transition from this type of work to the next.

5. Focus on achieving the main objectives of the lesson. The stage of assessing the lesson from the point of view of attainability of the key goals is very important and can take a significant amount of time, taking into account possible adjustments to the plan.

Thus, lesson time management covers not only lesson planning and implementation of the plan, but also the subsequent analysis of the results. The effectiveness of time management can be assessed taking into account all together points leasted above. Creating a wellmanaged learning environment could be an undeniably demanding task at distant learning.

\section{Time-management in remote teaching}

Many universities offer different e-learning technologies for distance studying, as well as a kind of support for their classic teaching because of quarantine. The remore teaching consists of ab academic staff member, an undergraduate and the course. Let's look at the issue of time management from the point of view of these three participants of the remote teaching system.

The term "time management" is widely used for many types of time managing activities. The widely-used context of this term is "Personal time management" referring to the set of habits, rules and recommendations on how to manage one's personal time effectively. Although the personal time management plays key role in the educational process efficiency, there are also some other meanings of this term, referring mostly to the course time management and possibilities of a remote teaching system.

Remote teaching puts a lot more responsibility on the academic staff members, giving them more workload as learning technologies change rapidly and academic staff members have to keep up with innovation, devoting a lot of time to preparing relevant materials to ensure the best learning outcomes. Consequently, teaching is becoming even more stressful, intense, less personal and the curriculum is becoming more 
inflexible and focused on controlling academic staff members. Moreover academic staff members who teach foreign languages are seen to be distinctive from the ones of other disciplines in terms of the nature of the subject, the content of teaching, the teaching methodology, an academic staff member- an undergraduate relationships, and contrasts between native and non-native speakers. Many of the language tasks encouraged by contemporary language teaching methods and techniques are believed to foster creativity in undergraduates-specifically those involving undergraduate-centered, interaction-based, and open-ended elements, and are consequently aligned with claims of supporters of establishing creative thinking.

Time management behavior can be defined as a dynamic combination of time assessment, goal setting, planning, and monitoring. You may say, time management behavior is a predictor of perceived control of time, which at least partially mediates the relation between time management behavior and wellbeing as well as job satisfaction.

The academic staff member's role in remote teaching is very demanding to self-discipline and obeying the deadlines. Undergraduates of course don't have self-discipline, but they wouldn't forgive if the academic staff member misses some deadline or doesn't fulfill his / her promise. The fact making the academic staff member's situation more complicated is simultaneous leading of more than one course and often number of other activities. So the academic staff member has to watch a lot of deadlines, manage a lot of tasks and administrate a lot of undergraduates' activities. Some common personal time management recommendations can be given, e.g.:

- Set up the to-do list for each course and mark the deadlines clearly.

- Manage courses regularly during the week. The week is the most common time element in the course, so it is a natural way to remember all necessary activities.

- Have regular timetable. Some people are more active during the morning, some during the night, so set up your regular working hours and do not change them too often. 
- While working on one task, don't interrupt the work. Other tasks will be done better after finishing the actual one. Moreover, the ability of concentration can be lost if switching between the tasks too often.

- Communicate efficiently with undergraduates. Give them clear and simple rules to minimize their questions. Answering same questions many times takes a lot of time. Work out the FAQ of the course to minimize undergraduates' questions in the next run of the course.

- Have a calm, pleasant and quiet environment for the work. Try not to be interrupted during the work. The work then will be more efficient.

All mentioned above are general recommendations. There are some other recommendations specific for remote teaching by the academic staff members:

- Course time point. Set up the time points for each course. Then merge these points into one list to see all deadlines clearly and to not forget any. Many software tools can be employed to manage the time points.

- Priority matrix. Let's imagine the table where columns belong to different courses and rows belong to priority levels. Then each cell describes an elementary task. Each task has its priority and course which belongs to. The nearer some deadline is, the higher priority the task has. Also the more important a task is the higher priority it has. There can be of course many more ways to manage all courses as best as possible. The goal is always the same - manage courses in the less possible stressing and time demanding way.

Also during remote teaching you deal with course time management, which influences both academic staff members and undergraduates. Each course consists of two periods: period of teaching and period of exams which follows immediately after the period of teaching. You should distinguish between pure remote teaching course without any face-toface contact between an academic staff member and undergraduates, and blended learning (includes classic teaching and remote teaching support).

Remote teaching course should have clear time point with clearly defined activities such as studying the e-textbook, making exercises, studying from other sources, making the training tests, and other activities suitable for the specific course. That is obviously that each course should contain deadlines for each activity. Otherwise, 
undergraduates will postpone all activities further and further, they will try to manage everything just during the night before the exam and it will dramatically influence the quality of their knowledge.

For the academic staff member preparing the course, it is important to consider each activity planned for the undergraduates from the point of view of the time consumption, importance and influence to knowledge, ability or skill.

So if you want to create some rules for our course, you should consider which application or learning management system you will use. And all recommendations could be divided into two groups:

- Learning management system ergonomics;

- Logging of all activities and their time consumption.

Chosen application is the passive part of whole process and can just help the active participants to fulfill their rules of efficiency. The learning management system ergonomics means that system is welldesigned to provide comfort during.

Both the academic staff members' and undergraduates' work, all parts are well accessible, clearly divided and understandably arranged. The most used parts or applications should be accessible with the less possible steps; however the less used applications can be hidden.

The chosen system should help academic staff members and undergraduates to provide more efficient teaching and studying. So logging all activities and their time consumption and understandable presentation of these data and relation between them is one of key services provided by remote teaching system.

According to the ECTS rules, one credit should be gained after 25-30 hours of work (meaning attending the course, making home tasks, doing other activities, etc.) of an average undergraduate. Taking this into account, you can see that in remote teaching the most of the undergraduates devote significantly less time to the studies than they should. So the first natural advice for undergraduates is: find out the time demand of each course and include it to your timetable. Then you will have higher success at the exams.

Studying remotely, make your timetable according to your time possibilities and demand of the courses. Doing activities regularly during each week helps undergraduates to study continuously and more 
efficiently. Than you will be able to spent sufficient amount of time and your knowledge will be better. You can see that more recommendations for academic staff members can be applied to undergraduates - all that flows from the common time management rules, so it is not worth to repeating them once more.

Time management is seen as a compass, which is mandatory for guiding to focus on what must be done according to the time given daily weekly or during the whole course.

\section{Teaching Smarter to Enhance Productivity}

The lesson is exactly the place where the individualities of the academic staff member and the undergraduate, their personal characteristics, desires and motivation collide. In addition, both of these sides meet within the framework of a particular educational institution, and therefore the content of course follows the curriculum of this institution. However, each academic staff memberhas the right to choose methods and forms of teaching based on the lesson goals.

Here it is necessary to mention a common mistake when the lesson plan is designed entirely from the point of view of the academic staff member's convenience, the convenience of explaining the material and does not take into account the peculiarities of the memory, attention, perception of undergraduates, their desires, motivation and their desire to manage their time.

Certainly all creative academic staff members usually ask themselves questions: "How to manage classroom time better or how to be sure that our undergraduates make the best use of the class time?" This question is very important during remote teaching or on-line lessons. Certainly a lot depends on academic staff member's classroom management skills:

- material you cover, the progress undergraduates have, the efficiency of the lesson, how interested the undergraduates are, etc. Very often you try to think for everyone and to predict all the issues. However, everything gets easier when you think of ways to make the undergraduates to take responsibility for their learning. The best way to do it is to develop habits. 
One of those habits is to teach our undergraduates the importance of time management from the very first day. It can be done through several activities and methodologies.

There are two main ideas.

1. Time the activities! This can sound like a cliche, however, all the academic staff member development courses (e.g. CELTA, TEFL) teach us to keep the timing of the activities and tasks right. Academic staff members want to make sure they cover several skills during a session, to keep the flow of the lesson as varied as possible and to keep up to the plan. Undergraduates learn to work faster or slower and try to fit in the time frame. In both cases, you need to do our estimations clearly, not to overtime or give them less time than necessary. This, surely, comes with experience.

The accepted approach here, according to the CELTA course, is to:

- set the time limit for the undergraduates before they start an activity;

- make sure they know how much time they have (share a timer on the screen);

- remind them periodically how much time they have left.

This definitely shapes the undergraduates' sense of time. Meanwhile, using visual aids to do that gives them a better chance of developing selfmanagement skills.

2. Hold competitions. That is an activity which undergraduates like most of all and it helps you to make their time management skills better. Create competitions (crosswords, puzzles, guessing games, etc.), time them for several minutes, see who first gets to the finish. To encourage all the undergraduates to take part I personally don't expect them to finish all the activity within the limited period of time. My instruction sounds like this: "You have 10 minutes to complete at least 12 sentences. Do as much as you manage to."

It sounds milder as in this case, you don't push the undergraduates to finish all the sentences, but to work within their capabilities. It also doesn't discourage the weak undergraduates who normally refuse working if they feel the challenge is too big.

There is an activity called " 2 Minutes Talk" what is a great activity not only to polish time management skills but also to work on enhancing 
speaking skills. Set the undergraduates in 3-s (you can dive them into different Zoom rooms and set the time), give them topics of discussion (football, free time, holidays, travelling, last Christmas, etc.), tell the undergraduates that they need to talk about each topic for 2 minutes. So, you have 3 roles in the group:

Undergraduate A - talks about one of the topics for 2 minutes (using target vocabulary if required).

Undergraduate B - takes the time and stops the speaker as soon as the time is up.

Undergraduate $\mathrm{C}$ - counts the sentences/key phrases the speaker used.

This task requires no preparation, the undergraduates need to be more focused, keeps everyone bust as all of them have a task and are responsible for it.

It has long been known that properly allocated time is a mechanism that improves memory, refreshes attention, and organizes thinking of undergraduates. It is no coincidence that various textbooks on public speaking recommend that every 15 minutes the audience should be distracted from the main topic and entertained with something. This is how much you are able to listen carefully and perceive information given.

In the modern society, the situation with attention is even more complicated. You are accustomed to five-minute news programs, thirtysecond advertisements and changing TV channels. You are used to taking information almost instantly and not watching for a long time if you are not interested. The peculiarity of thinking of a modern undergraduate (who perceives time very dotted) is distinguished by a high speed of perception of images, avoiding of accentuation on details; it is characterized by visuality, emotionality, associativity. That is why it is desirable to change the content of the lesson at least once every 15 minutes.

There are examples of the methodological techniques that fit the concept of "time management". These techniques organize, redistribute the time in the lesson, change the places of the lesson stages, the pace of individual tasks. As a result, the lesson becomes more dynamic, an action and a plot appears in it, a script is born from a simple sequence of 
points in the plan. An undergraduate will be interested in obtaining the information that is very important while teaching online.

I. Dynamic start of the lesson: 5-10 minutes

Icebreaker is a short, 5-10 minute introductory exercise, which has one goal to lift the mood in the group. The task should preferably be on the topic of the lesson. For example, a game of "gallows", when undergraduates have to guess some of the studied words written on the blackboard or a scramble game, when you need to assemble a word from the scattered letters. It takes little time, undergraduates perceive it positively. You can also instruct undergraduates in advance to become authors of this part of the lesson. And then each lesson will have a new original beginning.

An icebreaker doesn't have to be in the form of a game. Another option is to ask them to come up with one word that describes this day or give three adjectives that describe one undergraduate and the other one should guess who this undergraduate is. For this online activity you can use board Miro.

II. Main part of the lesson: 50-60 minutes

It must be understood that if the main part lasts 60 minutes, then, taking into account the rule "attention is fresh 15 minutes only", it is necessary to provide for either 4 different tasks or 4 different forms of performing tasks or breaks in between. You offer the following solutions to keep undergraduates focused throughout the main phase of the lesson.

1. It is logical if in the beginning of the lesson there will be tasks performed at a slow pace, and in the second part of the lesson, when the attention begins to decrease, there will be the tasks for speed execution. Slow assignments require reading, thinking, and concentration, for example, the detailed work with the text, translation, learning new grammar. Speed assignments in the second part of the lesson should be limited in time. For example, read an unfamiliar text in 5 minutes and convey its content or divide the group into teams and give some kind of a task, where the one who completes faster wins. It is by varying the speed of the lesson that you can avoid boredom and weakening of attention. Thus, you plan not so much the time of the lesson as its pace.

2. In any assignment, an academic staff member should look for interaction between undergraduates. For example, you can compose 
a dialogue based on the text you have read. You can divide the group into subgroups to complete a task. You can arrange a competition between subgroups. People of all ages love to play. The game will make a foreign language lesson more vivid and lively and the interest in the lesson sharply increases. Besides the use of games makes it possible to activate previously learned material in the speech of undergraduates, to develop speaking skills with the help of games, undergraduates can try on different roles, learn how to interact with game partners, to work in a team.

3. In any task, roles should be assigned. Assigning roles does not mean reading text by role or composing a dialogue. Any assignment where a undergraduate does something non-typical is already a role assignment. While reading the text, you can assign an interpreter who will translate by ear. A reviewer can be assigned to find errors in reading. You can assign someone responsible for searching for unknown words on the Internet.

4. You should look for ways that allow undergraduates to remember information more consciously. Namely, you should always strive to understand what they read. For example, after watching and discussing a video-podcast about a trip to Rio, give undergraduates some words as "churrasco", "mate", "Santa Teresa", "futevolei", explain that they can find these things in Rio de Janeiro and ask them to find out as much as possible they can about them and present this information.

This will already be a deviation from the usual rhythm of the lesson with great benefit for understanding the topic and enlarge their general knowledge.

5. Another way to involve undergraduates in a more conscious perception of the material is to activate memorization in the lesson. Everyone is used to the fact that in class they just listen, write down and learn by heart already at home.

But this is a waste of time, primarily the undergraduates' personal time, which they will spend on homework. It can be foreseen that at least some of the information was memorized by undergraduates at the lesson. For example, you can arrange a competition between subgroups. An assignment of the type: "you have 5 minutes to memorize new words, and then you will have a task with them." The advantages of this form of 
work are positive motivation. They don't risk getting a bad grade. The maximum trouble that awaits them is that their subgroup will lose. But the element of competition makes them learn words with much more enthusiasm than when preparing for a lesson.

One more way to help undergraduates learn as much as possible directly during the lesson is multiple repetitions of the same lexical units in different forms of work - in texts, dialogues, exercises. And another way is to ask undergraduates to come up with mnemonics for memorizing new words. That is, find phonetic and semantic associations in the mother tongue.

6. By changing the sequence of the stages of the lesson, it is easy to increase the motivation and attention of undergraduates. You can first explain the complex material and at the end of the lesson set aside another 10-15 minutes for self-note taking, so that everyone who misunderstood something could slowly figure it out or ask questions. The task is the same, the effect is the opposite. Surprisingly, such a boring and elementary type of work as writing down rules fits very well in the final stage of the lesson, when undergraduates are already tired of listening and want to read the material on their own. So the sequence of tasks is also important.

7. Change activities and unusual forms of tasks. The main rule here is to repeat the same type of activity as rarely as possible. You can simply read and translate the text, you can find synonyms, antonyms in it, you can listen to how the voice of Google Translate reads it, you can find the etymology of some words. There are not so many classes in the semester, so you can think of several techniques to do the same thing in different ways. You can ask words individually, in teams, in pictures, in mind-maps. Preparing this stage of the lesson, you plan not the time, but the change of activities. You are planning how you will change the monotonous flow of the lesson. You plan not the time, but how to diversify this time.

8. "Breaks". These are small, 3-5 minute exercises to develop memory and attention. They can be done between different stages of the lesson, or they can be used to break up too long text. For example, "snowball game" or give the task to repeat and add something to the sentence on the topic of the lesson. 
You can read two lists of words, ask to remember which word was not named in the second list.

You can read one list of words and ask to say which word was logically odd out.

III. Final part: 20-35 minutes

This is the most difficult part of the lesson for concentration.

1. You can show a video on the topic of the lesson or play a game using, for example, platform "Kahoot". This task is best given at the very end, as it is perceived by undergraduates as a kind of reward for work, a moment of relaxation and entertainment.

2. You can schedule a test at the end of the lesson. In contrast to watching a video, this ending of the lesson is perceived more as a punishment, but the goal will be achieved - undergraduates will be concentrated and efficient.

3. You can warn at the beginning of the lesson that at the end there will be a test on the material just passed. Undergraduates will listen very carefully and remember, because writing such a test is a rather difficult task. And again you see that the same kind of activity would occur slowly and monotonously at the beginning of the lesson, but quickly and dynamically at the end.

The main problem that interferes with the rational use of time at the lesson is the underestimation of the role of undergraduates in pedagogical process. In traditional planning, the academic staff memberacts as a subject managing time in the lesson, and the undergraduate acts as a subordinate or as an object. This does not take into account the peculiarities of perception, memory and attention of undergraduates. When a person becomes a subject, not an object of time, it flows for him / her in a different way. At the beginning of the class, when attention is still fresh, undergraduates can be in their usual role: the recipients or consumers of information who are "entertained" by the academic staff member. But in the second part, you must try to change their role to a more active one - the role of the participants who influence the course of the lesson, find out new information, make decisions on their own. 


\section{CONCLUSIONS}

The main things in pedagogical time management are to achieve maximum comfort for perception and memorization of information, the competent use of knowledge about the physiology of memory and attention. The goal of time management in pedagogy is to help the academic staff member to work out a plan so that the pace and sequence of tasks, pauses, a variety of methodological techniques make the lesson exciting and interesting. Some examples of the methodological techniques that fit the concept of "time management" suitable for on-line lessons were given.

A specific disadvantage of remote teaching for academic staff members is the "round-the-clock workload" due to the need to create updated materials specifically for online classes, post them on resources, conduct consultations and video conferences, maintain contact with undergraduates, and monitor and test knowledge.

Some rules for academic staff members, undergraduates and also for remote teaching developers were suggested. However, these rules can help just partly. The most important thing for everybody is a selfdiscipline, motivation and willingness to make the best. The mentioned recommendations can just improve the educational process efficiency, which is already quite high. To the people without time-managemet, selfdiscipline, motivation and willingness, noone rules and recommendations can be useful.

\section{SUMMARY}

The article deals with the notion "time management". It is the process of organizing and planning how to divide your time between specific activities. Good time management enables you to teach smarter - not harder - so that you get more done in less time, even when the time is tight and pressures are high. Failing to manage your time damages your effectiveness causes stress for undergraduates.

The potential of remote teaching is unlimited. Obviously, remote teaching programs and courses exist and will remain in the future, but there are still many unresolved issues that need to be clarified and explored. Although remote teaching may be as effective as regular 
classroom learning, but it cannot be argued that remote teaching can replace traditional learning.

\section{REFERENCES}

1. Реунова М. А. (2013). Тайм-менеджмент как педагогическая технология: Письма в Эмиссия. Оффлайн: электронный научный журнал. № 1. URL: http://www.emissia.org/offline/2013/1947.htm.

2. Соколов И. М., Железнякова Н. А., Гафанович Е. Я., Коньшина Л. Е., К Конобеева Е. В. (2014). Организация занятий в группах студентов 4-го курса медицинского университета с использованием принципов тайм-менеджмента. Альманах современной науки и образования. № 12(90). С. 116-119.

3. Baer, M., \& Oldham, G. R. (2016). The curvilinear relation between experienced creative time pressure and creativity: moderating effects of openness to experience and support for creativity. Journal of Applied Psychology. No 91(4), P. 963.

4. Essential time management skills. URL https://www.coachingpositiveperformance.com/17-essential-timemanagement-skills/.

5. Etzel, Barbara. \& Thomas, Peter (1996). Personal Information Management Tools and Techniques for Achieving Personal Effectiveness. Great Britain : Biddles Ltd Guildford and King's Lynn, London.

6. Kornyeyeva, O. M. (2015). Time management as a means of increasing the undergraduate's progress in higher education. Problems and prospects of the formation of the national humanitarian and technical elite: zbirny'k naukovy'x pracz'. Kharkiv, NTU “XPI” 44(48), 309-318. 